Trinity University

Digital Commons @ Trinity

School of Business Faculty Research

School of Business

2012

\title{
An administrative mess: A case study from the officiating community
}

Stacy Warner

Jacob K. Tingle

Trinity University, jtingle@trinity.edu

Pamm Kellett

Follow this and additional works at: https://digitalcommons.trinity.edu/busadmin_faculty

Part of the Business Commons, and the Sports Studies Commons

\section{Repository Citation}

Warner, S., Tingle, J. K., \& Kellett, P. (2012). An administrative mess: A case study from the officiating community. Sport Management Review, 15(3), 368-380. doi: 10.1016/j.smr.2011.11.003

This Post-Print is brought to you for free and open access by the School of Business at Digital Commons @ Trinity. It has been accepted for inclusion in School of Business Faculty Research by an authorized administrator of Digital Commons @ Trinity. For more information, please contact jcostanz@trinity.edu. 


\begin{abstract}
This case is written for instructors of classes focused on strategic management, organisational behaviour, human resource management, and/or an officiating course. The case highlights the numerous administrative processes a new employee in a sport organization would face. Although the case is fictional it is based on the authors' personal and professional experiences in athletics administration and officiating, and further draws upon the authors' research in the area of officiating. Consequently, this case study was constructed based on firsthand observation, interviews and conversation with numerous officials and administrators, and through the examination of documents frequently used to manage officials. As a result, the case provides an opportunity for students to critically evaluate and address: 1) a sport organisation's policies and procedures; 2) issues related to human resource management within a sport setting; 3 ) the managerial response after an organisational failure.

Keywords: referee; recruitment; retention; organisational behaviour; strategic management
\end{abstract}




\section{Teaching Note}

Officials and referees are essential to sport, yet they are rarely considered and discussed in the sport management literature. Thus, the aim of this case study is two-fold. First, the case provides a realistic administrative challenge for future sport managers to consider. It is not uncommon for students to enter into their first job having to replace an employee, who did not leave behind a clear set of directions or list of administrative processes, policies, and procedures on how the job has been done. Second, the case highlights officiating and helps bring the importance of officials in sport and sport development to the forefront. Almost all sport organisations have a coordinator of officials' position, and it is beneficial for students to understand the role and its challenges. The coordinator of officials' administrative responsibilities requires a skill set that is transferable to numerous administrative positions in sport. Thus, the case was designed to be engaging and relatable for sport management students, and multi-faceted enough to be used in variety of sport management courses. The Appendices contain pertinent documents for the students to review, examine, and consider in light of the case.

\section{Case Synopsis}

Davis Tripp is a recent graduate who was just named the coordinator of officials of the Montana State High School Athletic Association (MSHSAA). Tripp is faced with a series of three major issues that he must address after replacing a longtime employee. First, he must figure out how to better recruit and retain officials. Thus, sport marketing, human resource management, leadership and organisational behaviour knowledge must be applied. Secondly, Tripp must address the lack of 
administrative policies and procedures related to the officiating program. This overarching issue should encourage students to be innovative and strategic in tackling this problem. Finally, Tripp must utilise his public relations and communication skills to respond to an incident where poor officiating resulted in negative media attention.

\section{Assignments and Class Discussion}

The case is multifaceted and therefore relevant for use in a wide variety of sport management courses, in undergraduate or postgraduate level of study. There are a range of sources of theory that can be applied to the case, and the level of theory that is encompassed as part of the instructor's needs would determine the use of the case in undergraduate or postgraduate level coursework.

The overriding pedagogical objectives of this case are to sharpen students' strategic thinking abilities about the underexplored context of managing officials. Students are asked to analyse the situation of officials in the MSHSAA from the perspective of Tripp in terms of overall performance (in core activities of recruitment, retention and quality) and to draw sound conclusions about what actions management might take in light of all the relevant circumstances. It is suggested that this case be used in the second half of a semester, as students will require a grasp of the complexities, nuances, and constraints of working and managing in sport.

Since there are variety of ways in which sport management is delivered globally (e.g. on-campus, online, lectures, tutorials) in a variety of institutions with diverse student-types and class sizes, a range of case exercises and assignments 
that complement the case have been devised. Throughout the teaching note, there are exercises and assignments that can be completed individually, in groups, or as facilitator-led activities. Instructor use of this case in each of the following courses is suggested below.

\section{Human Resource Management in Sport Courses}

After successfully completing the case, students will be able to:

1) Identify and discuss issues related to employee recruitment and retention,

2) Articulate the importance of employee orientation, training, and (re)certification,

3) Discuss the importance of performance evaluations and perceived fairness in the workplace, and

4) Display an awareness of gender discrimination and sexual harassment issues, and be able to articulate how to address such issues.

Instructors of human resource management courses might find this case particularly useful as it highlights issues related to hiring, training, employee retention, work-family balance, and performance evaluations. A supplemental reading assignment such as Kellett and Shilbury (2007) and Kellett and Warner (2011), which speak to referee attrition and retention, could be used for more indepth analysis of the case. Other readings such as, Haney (1995) and Kearney and Tingle (1998) provide information related to employee evaluation. Furthermore, Dixon and Bruening's $(2005,2007)$ exploration on work-family conflict and Taylor and McGraw's (2006) research on Human Resource Management in sport organisations may also be useful ancillary readings. Students could also be 
encouraged to review Ortiz-Del Valle v. National Basketball Association (1999) for a more in-depth discussion on gender discrimination in relation to female referees. The following questions would guide a discussion for a human resource management course.

1) If you were Tripp, how would go about ensuring that more officials are retained?

2) The appendices provide an evaluation form coaches have been asked to fill out after every game or contest (See Appendix C).

a. If you were in Tripp's position, would you change this form and if so, how?

b. Describe what you would then do with the completed coaches' evaluation forms?

3) If you were to implement a training program for MSHSAA officials what would it look like?

4) It seemed from the case that some referees are facing issues related to work-family balance. In an effort to retain more officials, how would you address this issue?

5) In the case Amy Summit indicated that some gender discrimination or sexual harassment might be taking place among the officials. How would you handle this?

6) From Amy Summit's description of her experience of a referee, and from your knowledge of management of women in sport organisations, what human resource management actions require greater attention if Tripp is 
to realise his goals of recruiting and retaining more females? Why might those strategies be successful? What potential pitfalls should Tripp consider?

7) Tripp discovered numerous complaint and incident reports that were never addressed. If you were to create a policy on how incidents will be handled, what would you include? Right now, just a simple report form exists (see Appendix B).

Sample assignments for this course might include:

1) Students could be asked to write specific policies geared at improving the retention of officials. Examples might include work-family policies, pay incentive policies, or policies that address gender discrimination.

2) In small groups (or as individuals) students could prepare an in-class presentation describing a new evaluation and scheduling assignment procedures for officials. Students can choose to either use Appendix B as a reference or design a different evaluation form to be used by coaches. The presentation would be designed to explain the new evaluation system to officials. Students not presenting could be encouraged to ask questions as if they were officials who would be impacted by the new system.

3) In small groups (or as individuals) students could role-play how they would handle a phone call from a coach who was disgruntled that an official that he has repeatedly given low evaluations to has been again assigned to his games.

4) Students could be required to undertake a web based search for promotional materials aimed at recruiting new officials. Sources might include YouTube, 
websites and social media sites of referee associations or sport organisations as well as 'unofficial' websites and social media sites of those interested in refereeing. The instructor could then lead a class discussion on the common recruiting themes and recruiting tactics the class identified. Students might be instructed to take particular note of how material from referee associations and sport organizations differs (if at all) from the information obtained from unofficial sites.

\section{Organisational Behaviour or Strategic Management Courses}

After successfully completing the case, students will be able to:

1) Demonstrate the ability to conduct a goal setting meeting with an employee,

2) Explain the importance of organisational trust in a sport management setting,

3) Detail the elements involved in successful organisational change, and

4) Identify steps involved in the strategic management process.

Instructors could use this case in organisational behaviour or strategic management courses to discuss issues associated with managing an inexperienced administrator, the complexities surrounding organisational change, the importance of establishing organisational trust, the value of setting S.M.A.R.T. goals (i.e., specific, measurable, attainable, relevant, and time-bound), and the difficulties of decision-making in a fast-paced work setting.

Instructors in graduate level classes or those doing extended units on leadership and its relationship to organisational change are encouraged to have students read Blanchard (2010) and/or Schein (2010). For those classes with shorter units on leadership, chapters four-eight in Blanchard would give students a good understanding of 
situational leadership and how they might utilise Blanchard's Situational Leadership Model in their future role as a sport manager. Additionally, courses with shorter units on organisational change might have students read chapters 12-13 in Blanchard and 17-19 in Schein. As a supplement to Schein's text, MacIntosh and Doherty (2007) can be utilised to facilitate a discussion on organisational culture in a sport context.

Establishing trust in organisations is an important aspect of change, leadership, and improved performance, therefore, instructors could encourage students to read Adler and Adler (1988), Dirks (2000), Elsass (2001), Fink, Pastore, and Riemer (2003), and/or Turner and Chelladurai (2005). Literature from educational leadership can also be used to supplement a course unit on organisational trust. Specifically, Hoy, Gage, and Tarter (2006) and Tschannen-Moran and Hoy (2000) will give students a strong foundation in the theoretical underpinnings of organisational trust research. Instructors could plan an in-class discussion focusing on how the suggested educational leadership readings might apply in a sport management context.

To facilitate a discussion of goal setting, instructors are encouraged to introduce students to the seminal work by Blanchard and Johnson (2003). If an instructor has already chosen to use Blanchard (2010), chapter eight specifically addresses goal setting. For officiating specific courses or for instructors focusing on the development of decision-making and expertise, students are encouraged to read Gladwell $(2005,2008)$, MacMahon and Starkes (2008), MacMahon, Starkes, and Deakin (2007) and/or MacMahon, Helsen, Starkes, and Weston (2007). The following questions would guide a discussion for an organisational behaviour or strategic management course. 
1) If Ed Rosen were to take a Situational Leadership approach, how would he manage Tripp's first six months on the job? Read Blanchard (2010) chapters four-eight and examine Appendix A for the job description for the MSHSAA coordinator of officials and outline some measures for which Ed and Tripp could partner for performance.

2) What specific steps should Tripp use to begin creating trust between the MSHSAA and its officials? And its coaches? Specifically, how might Tripp use the findings from Adler (1998), Dirks (2000), and Hoy, Gage, and Tarter (2006) to inform his approach to trust development and maintenance?

3) How might Tripp approach the process of changing the culture of the MSHSAA? In particular, how might he change the culture of gender discrimination?

4) What goals (short-term, medium range, and long-term) should Tripp have in his role as coordinator of officials? What goals should Rosen have for Tripp and for the MSHSAA officiating program?

Sample assignments for this course might include:

a) Divide the class into small groups and allow students to role-play the goalsetting meeting with Davis Tripp and Ed Rosen. The remaining group members should observe the meeting and provide feedback for both Tripp and Rosen. Each student will have an opportunity to play Tripp, Rosen, and to observe.

b) From the perspective of Rosen, students could submit a brief writing assignment diagnosing Tripp's development level by assessing his 
competence and commitment. The Situational Leadership Model (Blanchard, 2010) could be as a guide.

c) Give students 10-minutes to prepare a SWOT analysis for the MSHSAA's officiating program. The instructor will then lead the class in a large group SWOT analysis.

d) Provide students with the task to conduct an analysis of the MSHSAA's officiating mission, stakeholder, values, and objectives. They should be asked to write a mission statement, identify key stakeholders, and develop organisational objectives based upon stated core values. Instructors can have students submit this analysis as a written assignment or as an in-class presentation.

e) Using the information from the MacMahon studies, have students design an officials' development program.

f) In small groups (or as individuals) students could prepare an in-class presentation describing the change strategy Tripp should employ. The presentation should address the phases of planned change, recommendations regarding an incremental or transformational change, and what specific strategies (e.g. force-coercion) they would employ. They should also address how they would manage resistance to their change strategy.

g) Students could also be encouraged to complete an online activity. Increasingly, there are third party providers who offer to train officials in all sports, and in particular in basketball. Third party providers (TPP) make money from providing training to individuals wishing to develop their skills. 
One example that promises to 'fast track' basketball referees to the professional levels is located at the following web address. Students should view this clip for the exercise:

http://www.youtube.com/watch?v=pFD6Tu7EvzM

i. One of Tripp's major tasks is to recruit and retain basketball officials in MSHSAA as well as to ensure consistency in officiating performance. What opportunities does a TPP basketball official development program provide for Tripp? What threats might it provide? Prepare a table with two columns—on labelled 'Threats' and the other labelled 'Opportunities' to guide the development of the answer to this question.

ii. Based on your answer to Part 1, and answers to previous questions in this section, should Tripp engage the TPP in his future strategy for development of officials? Why or why not?

\section{Teaching Points:}

There are a range of activities and assignments that have been designed for this case study. It is not necessary to complete all of the activities and exercises in each of the topic areas, however, all of the activities can be completed as standalone assignments (perhaps excluding the discussion questions that are sequentially linked, the activities are largely independent). The way in which to construct the learning activities for each particular class and delivery mode (on-campus, online, small or large class size) is up to the discretion of the instructor. For example, some of the activities might be assigned as preparation for students to complete before the assigned class/contact time. Other 
activities might be chosen to orient students to the case study and be completed as a 'warm up' to the in-class or contact time activities. 


\section{References}

Adler, P. A., \& Adler, P. (1988). Intense loyalty in organizations: A case study of college athletics. Administrative Science Quarterly, 33, 401-417.

Blanchard, K. (2010). Leading at a higher level: Blanchard on leadership and creating high performing organizations $\left(2^{\text {nd }} E d\right)$. Upper Saddle River, NJ: FT Press.

Blanchard, K., \& Johnson, S. (2003). The one minute manager. New York: Harper Collins.

Dirks, K. T. (2000). Trust in leadership and team performance: Evidence from NCAA basketball. Journal of Applied Psychology, 85, 1004-1012.

Dixon, M. A., \& Bruening, J. E. (2005). Perspectives on work-family conflict in sport: An integrative approach. Sport Management Review, 8, 227-253.

Dixon, M. A., \& Bruening, J. E. (2007). Work-family conflict in coaching I: A top down perspective. Journal of Sport Management, 21, 377-406.

Elsass, P. (2001). Trust and team performance in NCAA basketball. The Academy of Management Executive, 15, 137-138.

Fink, J. S., Pastore, D. L., \& Riemer, H. A. (2003). Managing employee diversity: Perceived practices and organisational outcomes in NCAA Division III athletic departments. Sport Management Review, 6, 147-168.

Gladwell, M. (2005). Blink: The power of thinking without thinking. New York: Little, Brown and Company.

Gladwell, M. (2008). Outliers: The story of success. New York: Little, Brown and Company.

Haney, M. W. (1995). Employee evaluation. Fitness Management, 11, 38-40. 
Hoy, W. K., Gage, C. Q., \& Tarter, C. J. (2006). School mindfulness and faculty trust: Necessary conditions for each other? Educational Administration Quarterly, 42, 236-255.

Kearney, J. S., \& Tingle, J. K. (1998). Evaluation of student employees: Why, who, how, when, what, and where. Recreational Sports Journal, 22, 45-48.

Kellett, P., \& Shilbury, D. (2007). Umpire participation: Is abuse really the issue? Sport Management Review, 10, 209-229.

Kellett, P., \& Warner, S. (2011). Creating communities that lead to retention: The social worlds and communities of umpires. European Sport Management Quarterly, 11, 475-498.

MacIntosh, E., \& Doherty, A. (2007). Extending the scope of organisational culture: The external perception of an internal phenomenon. Sport Management Review, 10, 45-64.

MacMahon, C., \& Starkes, J. L. (2008). Contextual influences on baseball ball-strike decisions in umpires, players, and controls. Journal of Sports Sciences, 26, 751760.

MacMahon, C., Starkes, J. L., \& Deakin, J. (2007). Referee decision making in a videobased infraction detection task: Application and training considerations. International Journal of Sports Science and Coaching, 2, 257-265.

MacMahon, C., Helsen, W. F., Starkes, J. L., \& Weston, M. W. (2007). Decision-making skills and deliberate practice in elite association football referees. Journal of Sports Sciences, 25, 65-78.

Ortiz-Del Valle v. National Basketball Association, 42 F. Supp.2d 334 (S.D.NY, 1999). 
Schein, E. H. (2010). Organizational culture and leadership (4 $4^{\text {th }}$ Ed.). San Francisco: Jossey-Bass.

Stern, J. (2009, December). How we make decisions. Referee, 34(12), 32-35.

Taylor, T., \& McGraw, P. (2006). Exploring human resource management practices in nonprofit sport organisation. Sport Management Review, 9, 229-251.

Tschannen-Moran, M., \& Hoy, W. K. (2000). A multidisciplinary analysis of the nature, meaning, and measurement of trust. Review of Educational Research, 70, 547593.

Turner, B. A., \& Chelladurai, P. (2005). Organizational and occupational commitment, intention to leave, and perceived performance of intercollegiate coaches. Journal of Sport Management, 19, 193-211. 


\section{An administrative mess: A case study from the officiating community}

Davis Tripp sat in his office at the Montana State High School Athletic Association (MSHSAA) and felt overwhelmed as he looked through the reports and binders that were left from his predecessor. It was his first job out of college. Although he had zero managerial experience, the MSHSAA executive director Ed Rosen was confident that Tripp would succeed as the coordinator of officiating. Rosen felt that Tripp was just the person to revamp the image of the officiating organisation and to address many of the issues that have recently surfaced.

Tripp served as a basketball and baseball official while he was studying for both his undergraduate and post graduate degrees in Sport Management at Montana University. When it became obvious that Tripp wouldn't have the opportunity to continuing playing basketball in college, his father, a high school basketball coach, encouraged him to try officiating. He quickly worked his way up the ranks, and developed a strong reputation as a competent and well respected official. Tripp stood out because of his professionalism, work ethic, and obvious commitment to being the best official he could be. Tripp also stood out because overall, the number of quality officials in Montana was dwindling (see Table 1), and he was one of the few young officials who seemed to take his role in the games very seriously.

When Jack Mason told his friend and colleague Ed Rosen he was retiring after 45 years of serving as the coordinator of officials, Rosen felt a sense of relief and was excited to fill the position. Rosen had known a change was needed; the officiating program had been slowly falling apart for some time. However, he was never able to work up the courage to let go of Mason, his long-time employee and his friend. Mason 
had been resistant to change (including using technology to improve communication and training), and was known to hold grudges against anyone who challenged him. He also had a reputation for belittling officials, and a knack for scaring off new officials. The officiating program clearly suffered from his lack of leadership and unwillingness to change, but Mason hadn't done anything so egregious to warrant disciplinary action. While there had been complaints from parents, fans, and coaches coupled with the dwindling numbers of officials, Rosen never felt compelled to damage the friendship by asking Mason to step-down. Rosen knew that Mason's replacement would need to be personable, passionate about officiating, and innovative (See Appendix A for job description). Although Rosen had only interacted with him a few times, Tripp had made an impression. When Tripp's application for the job of coordinator of officials landed on Rosen's desk, he instantly felt Tripp would be a great fit. He also knew, however, it would be risky to put someone with such little job experience in the role. After talking to several coaches and administrators at schools where Tripp had officiated, Rosen became more confident that Tripp could handle the job. After a round of interviews with the MSHSAA executive committee, Tripp was considered to be the most qualified candidate and offered the job. Rosen knew that he would have to mentor Tripp, and provide him with lots of support to set him up for success.

Wanting to determine Tripp's current level of preparation, the first task Rosen assigned Tripp was to review the various reports and documents in the binders Mason had left behind, with the view to develop goals for the year, and create a set of steps that would lead to achieving each goal. Rosen and Tripp then scheduled a meeting to discuss the goals and action plan a week later. Although Tripp had to manage officials for all 
sports, basketball was the most prominent sport in Montana (and the sport with which he was most comfortable). Therefore, he knew he needed to address issues related to basketball first and by doing so it would set the tone for the remainder of the officiating program. Therefore, Tripp's first decision was to use the basketball officiating program as a place to pilot test new ideas. He would proceed slowly with adjustments to the other sports and would base changes on what worked for the basketball officiating program. While Tripp was thrilled to be the new coordinator of officials, he was about to find out the enormity of the challenge before him.

One of the first reports that Tripp discovered was a chart indicating the annual number of MSHSAA registered officials (see Table 1). He had known that the overall numbers of high school athletic officials were declining in Montana, but he wasn't aware of the extent. Tripp knew this was an area he would have to address soon. Based on Tripp's experience he knew that he would have never become an official without his father's prompting. Under Mason's leadership the MSHSAA had solely depended on this type of word of mouth recruiting. They had no marketing materials or plan to create a marketing campaign geared at encouraging individuals to consider officiating. The number of female officials certainly reflected the lack of marketing to a greater extent.

Tripp knew of only a few female basketball referees and one in particular that he felt could give him insight into why the numbers of females were so low. Tripp and Amy Summit had officiated a few games together in the past, but their paths didn't cross at all the previous season. Tripp found Amy's number in the conference's database of officials and gave her a call. Tripp soon found out that Amy had quit officiating. Amy explained. “Tripp, it just wasn't an enjoyable experience anymore. I would show up at a school for 
a game, have no idea where the locker rooms were or who else would be officiating. I felt really alone, and unwelcome. It wasn't until I would arrive on the court at game time that I would meet the other officiating crewmembers that I was supposed to be working with. As soon as I would introduce myself to them, I quickly felt as though I was being judged simply because I was a female. I'm a highly-skilled referee, but they were assuming because I was female I knew nothing. The general attitude towards me was extremely condescending. Now every referee wasn't like that. A few, like you Tripp, would make me feel welcome. But overall my experiences were not good. As if the eyerolls and snide comments they would make to one another about me weren't enough, the sexual innuendos made me feel even more uncomfortable. I didn't hesitate to stand up for myself, but after a while I realised there was no support above me to do anything about it. It just wasn't worth it, so I walked away." Tripp empathised with Summit's situation, and told her he was committed to making the experience better for all referees, and for females in particular. He knew from browsing through online referee forums and reading trade publications that unfortunately, Summit's experience was consistent with other females who tried to break into the officiating profession.

Tripp knew that along with addressing the issues related to a lack of female referees, he needed to find out the reasons why more officials were not retained. After scanning the database of officials, Tripp surmised that on average officials were dropping out within a few years of starting. The experience factor is such a challenge because it goes beyond simply knowing and administering rules. In fact, in his experience, great referees are not only masters at their craft; they also have an artist's ability to see the world through multiple lenses. As Tripp read through his notes he remembered a class 
lecture that focused on the length of time required to become a great decision-maker or an elite referee. He recalled research that indicated that becoming an expert takes between 8,000 to 10,000 hours of purposeful training (see Stern, 2009). Furthermore, because referees don't have the ability to practice the way athletes do, it might take as long as 16 years for them to reach expert status. 'I have to figure out why these officials are quitting,' Tripp murmured to himself.

As Tripp pondered this question, he recalled a few articles he had recently read on coaching and officiating. Although he didn't have a family himself, Tripp knew from staying well informed on the research related to the nuances of working in sport that work-family balance was an important issue. For example, he had read a study by Dixon and Bruening (2005) regarding work-family conflict in sport. They noted that in the sport setting, many roles are characterised by long hours in non-traditional work times such as weekends and nights. This makes sport a particularly difficult setting in which to juggle family responsibilities—-for both men and women. Tripp wondered how this played out for officials given the long and odd hours that they work. He also knew of several colleagues who had quit refereeing shortly after starting a family. He felt that this issue was important to further consider in his review of reasons for officials to quit refereeing.

There were other interesting outcomes from the study by Dixon and Bruening (2005) that compounded the difficulties of work-family conflict, in particular for women. He considered that this might even be more specific to officiating than in other contexts within the sport setting. He remembered that Dixon and Bruening noted that sport is highly gendered and much of the control over work practices, structures, and policies are 
dominated by men. He followed their research and found that in a later study they examined the experience of work-life balance for female coaches who were mothers (Dixon \& Bruening, 2007). They found that the work culture and climate (dominated by men) was a major factor in their life and job satisfaction-and ultimately their intentions to leave the coaching role. In light of the discussion that Tripp just had with Summit, he recalled with some trepidation that the politics of scheduling and the 'good ole boy network' were alive and well in officiating.

In fact, he knew from Summit and anecdotal evidence from others, that this was frequently cited as a key reason for referees to drop out. Officials who were part of the male-dominated network would get "looked after" by being given first choice to officiate the better games. Those games considered to be better might be more convenient (meaning less travel required); be of a higher skill level and therefore an official might command higher pay rates; or be between teams where players and spectators were considered to be well-behaved. Tripp was getting the idea that women really didn't stand a chance in the 'good ole boy' network. In light of this revelation, he could appreciate that Summit's experiences were terrible, and shouldn't have happened—but based on the research, he could now clearly see why they had. He needed to devise strategies to begin to deal with this issue-but strategies needed to be grounded in the recommendations from theory (Dixon \& Bruening, 2005, 2007).

Tripp was also well aware of the abuse officials face from fans and how this stress impacted them (newer officials especially). After all, he had firsthand experience with abuse, but he had learned to deal with it. Tripp was also aware of some research that examined how long-term officials deal with abuse (Kellett \& Shilbury, 2007). This 
research noted that the informal social interactions that occurred between officials was also a site where learning would happen —in particular learning about how to deal with abuse. The research suggested that when officials interacted, they would learn from each other-as there was little formal training in the accreditation manuals about how to deal with spectator abuse and game-day interactions. It was clear to Tripp that developing a sense of community and camaraderie among officials could help temper and mitigate the stress, and indeed lead to some vital learning. In fact, he believed a strong sense of community among officials also played an important role--in particular in their retention (see Kellett \& Warner, 2011). After all, if officials can learn how to deal with abuse (a reason often cited for their departure from the role) this must have an impact on their willingness to stay in it. Tripp needed to find a way to improve the overall experience for referees, and equip them more appropriately for the role. He knew he had to consider numerous factors related to their recruitment, as well as retention.

Next, Tripp discovered a filing cabinet that was labelled "Complaints, Incidents, and Evaluations." The first drawer he opened had two big binders. These two binders were full of report forms, from officials to the association, which described unusual incidents and/or controversies that occurred during the games they officiated (see Appendix B). The forms were filled with negative incidents describing improper treatment by administrators at events and inappropriate behaviour from both fans and coaches. At this point, Tripp scoured the office looking for a policy and procedures manual to determine what the MSHSAA did with these forms after they arrived in his office. As his search yielded nothing to guide him, he quickly became defeated. Frustrated and feeling slightly overwhelmed, Tripp walked into Rosen's office to ask for 
assistance.

“Mr. Rosen, I just realised I don't have a policy and procedures manual in my office. And I'm just trying to figure out what the Association does with the officials' incident reports." Rosen smirked and replied, "Well Tripp, there is a three-hole punch in the copy room. When the reports arrive that is their first stop. Their next and final stop is the appropriately labelled file cabinet in your office." "Really? That is it?" Tripp said with disbelief. Rosen responded, 'I'm afraid so, Tripp. We don't have any written policies and procedures, and to my knowledge nothing has ever been done with the forms. It's time for a new system, I'm sure you'll come up with some great ideas." Tripp then ironically replied with a smile, "Well, we could at least move three-hole punch closer to the water cooler to increase the likelihood that the reports are actually read and discussed." Both men laughed with the realisation that a much bigger change was needed.

Back in his office, Tripp began browsing through the rest of the "Complaints, Incidents, and Evaluations" file cabinet. He turned to the section that was comprised of the coaches' evaluations of the officials for every game (see Appendix C). Tripp didn't even bother looking for the policy and procedure on what was done with these forms. Based on his previous conversation with Rosen, he instinctively knew nothing was done with these either. Mason had claimed that he reviewed them and used them to determine officiating assignments, but Tripp did not come across any cumulative evaluation reports for a single official. The individual evaluation forms were organised in chronological order by game date, and perusing the report Tripp could tell that poorly rated veteran officials were continuing to get a disproportionate number of playoff games compared to 
highly rated younger officials. With no formal written policies, it appeared that officiating assignments had been given subjectively based on Mason's opinion. Again, Mason had a reputation for holding personal grudges - to the detriment of some the coaches' highest ranked officials. Based on the officiating schedule and assignments, it appeared to Tripp that Mason's reputation may have been well earned.

Tripp also noted that coaches frequently reported on the "comments" area of their evaluation forms, that they were unhappy with the lack of consistency between officials in enforcing rules (See Appendix D for the notes Tripp took while reading the evaluation forms). Although there is a standard rulebook for each sport, the interpretation of the rules and their enforcement according to the coaches, seems to have been inconsistent among the officials. In order to be an official in the MSHSAA, all an individual had to do was pass a 100-question rules test. Despite annual revisions to the National Federation of High Schools (NFHS) rules, there was no follow-up on whether or not officials understood or were even aware of rules changes. Furthermore, there was no evidence that anything was done to help officials develop the ability to navigate the significant gray areas that existed between legal and illegal play. There was no formal training required or annual recertification for officials. After all, Montana was facing a shortage of officials and Mason hadn't wanted to make it more difficult to fill the schedule--even if it meant scheduling under-qualified officials to work games.

That scheduling decision (i.e., utilising under qualified officials) had obvious repercussions; parents, fans, players, and coaches have been disappointed in the officiating for the past few years. As Tripp was soon to learn, the disappointment quickly turned to outrage after the 2011 Montana State Boy's Basketball Championships. The 
Helena Raptors were down by one point with five seconds to go and they had to travel the length of the court and make a final shot. The Columbia Fall Tigers were the small town underdogs hoping to upset the current state champions. The Tigers seemed to have the advantage. As the Raptors player went to in-bound the ball, he stepped on the playing court before releasing the ball. It should have been the Tigers ball on the violation, but the referees missed the call. Then as the ball was being dribbled up the court, the entire crowd roared when another Raptor's player obviously travelled with the ball. The referees failed to make that call as well, and with time expiring, the Raptors player heaved a shot that miraculously fell through the hoop. The "buzz-beater" did not, in fact, beat the buzzer. The referees, however, counted the shot and quickly ran off the floor. The Raptors celebrated their repeat state title, while the Tigers stood in disbelief. The video clip of the last five seconds of the game was repeatedly broadcast over the news across the state (See Appendix E and F for reaction in media). After someone posted the clip on YouTube, it went viral and within two days ESPN crews were in Helena and Columbia Falls to get fans' and coaches' reaction to incident. ESPN showed clips of the incident when it happened, but they also planned to do a more in-depth follow up story in the summer when sporting news was slower. Since Mason was now retired, Tripp would have to be the spokesperson for MSHSAA on the incident. 


\section{Appendix A}

\section{Job Description for MSHSAA Coordinator of Officials}

\section{Montana State High School Athletic Association Coordinator of Officials Job Description}

\section{BASIC FUNCTION}

To develop, implement and supervise all activities associated with officiating for the Montana State High School Athletic Associations (MSHSAA).

\section{REPORTING RELATIONSHIPS}

The Coordinator of Officials reports directly to the Executive Director of the MSHSAA. In addition, he/she will work closely with the National Federation of High Schools (NFHS) on matters related to officiating development. The Coordinator of Officials must establish a positive working relationship based on cooperation and trust.

\section{SPECIFIC RESPONSIBILITIES}

- Formulate and monitor the identification, recruitment, training, assignment and supervision of officials for MSHSAA state playoff games. Work closely with league representatives and school district supervisors on matters concerning officiating and discipline.

- Develop and operate training camps for selected officials who will work postseason games. Develop a system of standardised rule interpretations and develop consistency in the level of officiating throughout the state.

- Work diligently to create and foster a positive environment in which developing officials can compete and hone their officiating for the betterment of the game.

\section{RELATED DUTIES AND RESPONSIBILITIES}

- Serve as a resource person and assist in identifying and promoting talented officials.

- Be available to assist them with issues pertaining to officiating development. Arrange the logistics for all meetings of supervisory and officiating staff.

- Prepare an annual report, including an officials' evaluation summary of the officiating program.

- Handle all incoming correspondence and grievances regarding MSHSAA officiating. Serve as a go between during conflicts between MSHSAA teams, coaches and officials on issues pertaining to officiating.

- Respond to all correspondence and questions concerning the interpretation of the playing rules from team personnel and officials. 
- Develop and manage a budget for the operation of the officiating program, including authorisation of approved expenses.

- Various other duties as assigned by the MSHSAA Executive Director.

\section{IDEAL CANDIDATE}

- A bachelor's degree with a major in education or sports administration is strongly preferred.

- A superior knowledge of officiating in at least one sport is essential. Strong interpersonal communication skills, writing skills, knowledge of publication procedures and visual instruction skills are all necessary.

- Organisational and leadership skills are essential.

- A minimum of five years officiating experience is necessary. Preferably, such experience should be at a variety of levels from grassroots to elite.

- Supervisory experience is preferred.

- The Coordinator of Officials must be willing to relocate to Helena.

- Out of town travel on weekends and throughout the summer is very much a standard part of the job.

- Computer skills are helpful and strongly preferred. 


\section{Appendix B}

Incident Report Form

\section{Montana State High School Athletic Association REFEREE INCIDENT REPORT}

A referee is to report any unusual incidents on this form. This form must be submitted to the Montana State High School Athletic Association immediately following the game in which the incident occurred. Referees should mail this form to Jack Mason, 123 Association Road, Helena, MT 87656.

Date: Time:

Location

Who was involved in the Incident?

Describe the Incident:

Who else witnessed the Incident?

REFEREE:

SIGNATURE: DATE: 


\section{Appendix C}

\section{Coaches Evaluation Report Form}

\section{Officials Evaluation Form}

\section{Montana State High School Athletic Association \\ Officials Evaluation Form}

\begin{tabular}{|c|c|c|c|}
\hline Game Date & Location & Opponent & Game Winner and Final Score \\
\hline & & & \\
\hline
\end{tabular}

Ratings: Officials are to be rated with a numerical grade for the categories listed below. Any rating of a 2 or lower must have a detailed description that can be used to improve future performance.

Scale: $\quad 5=$ Excellent

$4=$ Very good

$3=$ Average

$2=$ Needs Improvement

$1=$ Unacceptable

\begin{tabular}{|l|l|l|l|l|l|}
\hline 1. Communication with you and members of your staff & 1 & 2 & 3 & 4 & 5 \\
\hline 2. Professionalism & 1 & 2 & 3 & 4 & 5 \\
\hline 3. Level of care and respect for the game and its participants & 1 & 2 & 3 & 4 & 5 \\
\hline 4. Physical appearance & 1 & 2 & 3 & 4 & 5 \\
\hline 5. Hustle (did s/he keep up with the play) & 1 & 2 & 3 & 4 & 5 \\
\hline 6. Rules knowledge & 1 & 2 & 3 & 4 & 5 \\
\hline 7. Consistency with partners & 1 & 2 & 3 & 4 & 5 \\
\hline 8. Overall call selection & 1 & 2 & 3 & 4 & 5 \\
\hline 9. Control of the game & 1 & 2 & 3 & 4 & 5 \\
\hline 10. Compare this official to others you've seen this year & 1 & 2 & 3 & 4 & 5 \\
\hline
\end{tabular}

Use this space to discuss any ratings of 2 or lower. You may use the back if you need more room. 


\section{Appendix D}

\section{Tripp's Notes from coaches evaluations}

Common complaints from basketball coaches
Inconsistent calls
Lack of professionalism
Too many inadvertent whistles
Unaware of new rules adopted by association
Unfit - can't keep up with pace of the game
Poor officiating mechanics and techniques
Obvious lack of coordination among officials




\section{Appendix E \\ Newspaper Article on the Blown Call}

State Title Tainted by Officiating Miscues

Posted: Sunday, March 14, 2011

The Associated Press

Butte, MT (AP) -

Some notorious hoops history might have run through your mind after seeing the ending of the Helena-Columbia Falls boy's state championship basketball game Saturday night.

As everyone who has seen the replay knows the game clock expired before the winning shot was hoisted by MVP Joe Frederickson of Helena. Additionally, game officials missed two blatant violations leading up to the "winning" shot.

This is, of course, not the first team to lose by a controversial play at the buzzer. Go back to 2004 game between Butte and Great Falls East. The score was tied 56-56, and Butte got a steal and Phil Pattu was fouled taking a 15-foot jumper. Pattu made the first charity striper, but after the second shot missed, Butte's Tom Korverson and East's Dante Lopez collided on the rebound. Official Fred Mickyl called the foul on Korverson with no time left. After a brief huddle, the officials agreed to let him shoot and Lopez made both free throws to give Great Falls East its third title in five years.

I was at the Butte Civic Center that night, and in 25 years of covering high school basketball that still ranks first in terms of the most fan correspondence I've ever received after a specific game. Some specific concerns have produced more reader response, but no single game I've ever covered got people so furious -- both objecting to and defending that call.

What happened last night, however, might top that incident. Talk about the officials falling asleep.

The Raptors stepped onto the playing court during a throw-in, illegally, before inbounding the ball. But it wasn't called. Then the three-step hokey pokey at midcourt that wasn't called. Two dribbles later time appeared to expire before Carl Gustavson nailed a 35-footer to win the game.

The situation was utterly bizarre; the equivalent of a volleyball spike being 5 feet out of bounds, but called "in." To make matters worse, the officials didn't huddle or discuss possible alternative outcomes, they immediately raced off the floor, leaving bedlam in their wake. 
Coach Vernon Slawson, always effusive, struggled to find the right words. He also struggled to fight back the tears, as did his Columbia Falls players. It was difficult to tell following Saturday night's controversial loss whether Slawson was more frustrated or just downright broken-down. He had a right to be either.

"Two big-time violations," a dazed Slawson kept repeating. "I'll never forget this one."

Indeed, television replays showed that one Helena player committed a throw-in violation and another one traveled. And then - the winning shot that went in late.

Helena coach Emil Charleston said during his postgame news conference that he was unaware there were any violations or that the shot was launched late. Television replays, however, clearly supported Columbia Falls players and fans side of the story.

"These two teams are too good for that," said Slawson, whose Tigers (22-2) still had stunned expressions at the press conference. "It's not Helena's fault. It's not Coach Charleston's fault. ... It has nothing to do with Helena, and it has nothing to do with those players and those coaches. Unfortunately, it was a human error.

Afterward, confusion reigned at the Butte Civic Center, with more questions being posed than answers being given. The explanation from officials regarding the controversial ruling was, "We stand by the decisions made on the court."

Apparently, the Columbia Falls athletic director Rob Welsh was attempting to contact the MSHSAA coordinator officials even before the Tigers left the arena Saturday. But, apparently Jack Mason wasn't answering his phone.

And while Slawson commendably did his best not to pull Helena or Charleston into the dispute, he left little doubt that the win was tainted.

"This should not be tolerated," he said. "We have a question mark behind this game. In this day and age, it is obscene for the MSHSAA not to put the very best officials on the court for the state finals."

While they can appreciate Columbia Falls' frustration, nobody in Helena was apologising for the win.

Seven years later, though, we see that sometimes "human error" still happens. 


\section{Appendix F}

\section{Letter from State Representative for Columbia Falls' District}

Posted: March 17, 2011

Re: "State Title Tainted by Officiating Miscues"

The condition of officiating in Montana has reached a new low. To have a state title stripped from twelve hard-working young men, because the 'arbiters' of the game couldn't do their jobs is absolutely unacceptable. Having two major incidents in the span of seven years indicates someone at the top is not doing their job either. As a member of the committee which appropriates funds to the MSHSAA, I can assure you we will be closely examining how they work to improve the quality of officiating in this state. 
Table 1

Referees by the Numbers

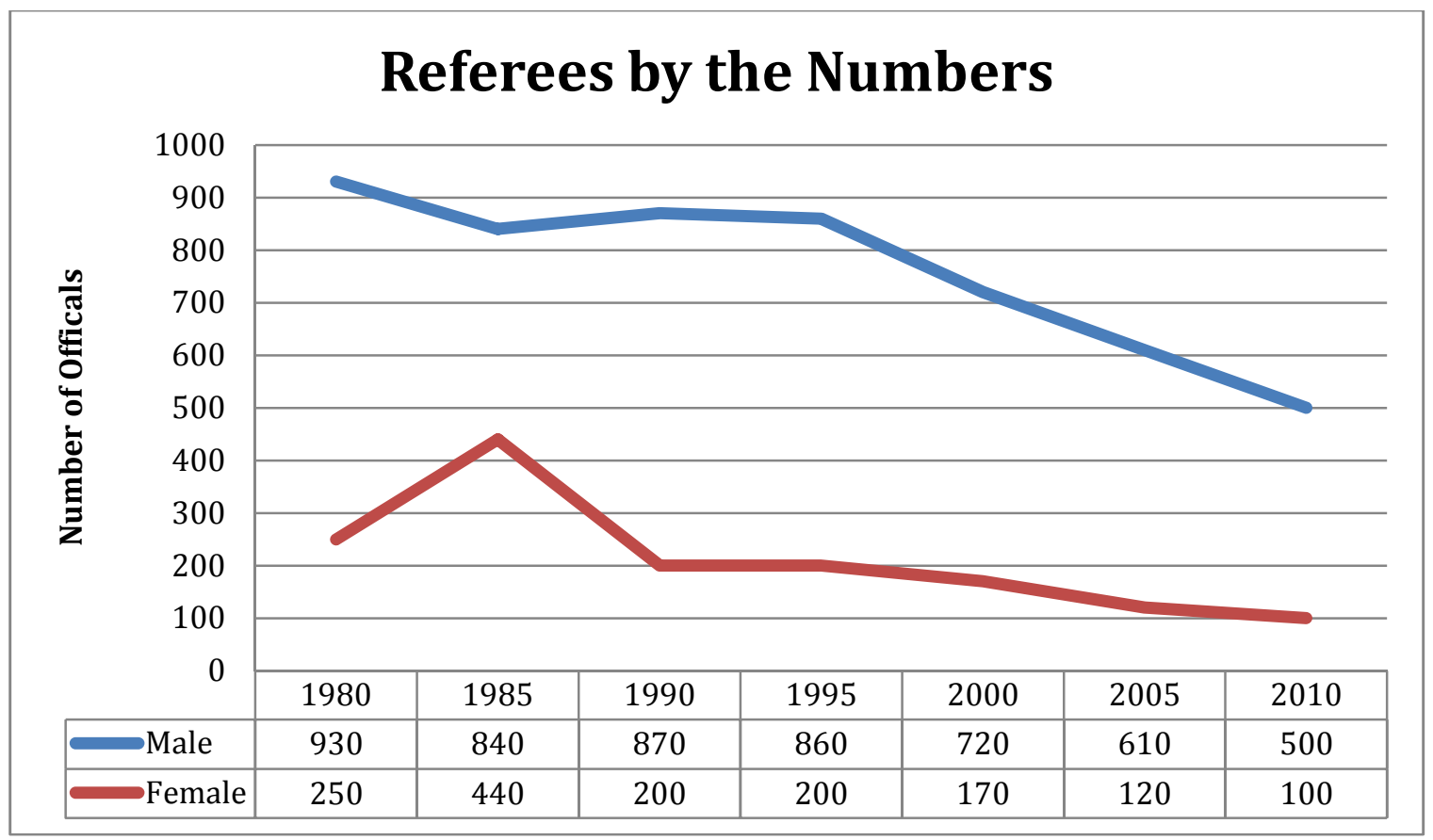

